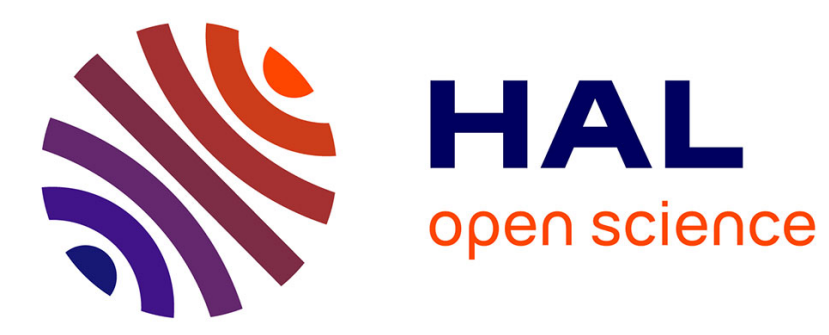

\title{
Transmission expérimentale du virus de la sharka par Brachycaudus persicae Passerini
}

\author{
A Fos, G Massonié
}

\section{To cite this version:}

A Fos, G Massonié. Transmission expérimentale du virus de la sharka par Brachycaudus persicae Passerini. Agronomie, 1993, 13 (6), pp.515-518. hal-00885570

\section{HAL Id: hal-00885570 https://hal.science/hal-00885570}

Submitted on 1 Jan 1993

HAL is a multi-disciplinary open access archive for the deposit and dissemination of scientific research documents, whether they are published or not. The documents may come from teaching and research institutions in France or abroad, or from public or private research centers.
L'archive ouverte pluridisciplinaire HAL, est destinée au dépôt et à la diffusion de documents scientifiques de niveau recherche, publiés ou non, émanant des établissements d'enseignement et de recherche français ou étrangers, des laboratoires publics ou privés. 


\title{
Transmission expérimentale du virus de la sharka par Brachycaudus persicae Passerini
}

\author{
A Fos, G Massonié \\ INRA, station de Zoologie, BP 81, F33883 Villenave-d'Ornon cedex, France
}

(Reçu le 30 juin 1992; accepté le 15 mars 1993)

\begin{abstract}
Résumé - Des expériences réalisées en laboratoire ont établi que $B$ persicae est un vecteur de la sharka. Les adultes, aptères ou ailés, ont transmis le virus à de jeunes plants de 2 cultivars de pêcher, GF 305 et Rubira. $B$ persicae pourrait intervenir dans la propagation naturelle de la maladie car il colonise toute l'année les vergers de pêcher, abricotier et prunier.
\end{abstract}

vecteur de virus / puceron / sharka / semis de pêcher / transmission expérimentale

Summary - Experimental transmission of plum pox virus by Brachycaudus persicae Passerini. In laboratory experiments B persicae, apterous and alate adults transmitted plum pox virus to seedlings of 2 peach cultivars, GF 305 and Rubira. It is considered that the aphid might participate in the natural spread of plum pox disease because it colonizes peach, apricot and plum orchards throughout the year.

virus vector / aphid / plum pox virus / peach seedling / experimental transmission

\section{INTRODUCTION}

La sharka est une virose grave des arbres fruitiers à noyau (Anonyme, 1974b; Lansac et al, 1982). La maladie est transmise par des pucerons suivant les modalités des virus non persistants (Kassanis et Sutic, 1965). Le verger est un lieu de passage pour les ailés de diverses espèces de pucerons, inféodés ou non à la culture (Labonne et al, 1988 ; Avinent et al, 1991). Cependant la majorité des espèces de pucerons connues comme étant des vecteurs en conditions expérimentales (tableau I) colonisent les arbres fruitiers à noyau (Massonié, 1976; Llacer et al, 1992) et des études épidémiologiques suggèrent que ces pucerons des arbres fruitiers ont un rôle essentiel dans la propagation de la maladie (Jordovic, 1965 ; Minoiu, 1973).

D'après les travaux publiés à ce jour, l'aptitude de Brachycaudus persicae Passerini, ou puceron noir du pêcher, à transmettre le virus de la sharka n'a pas été étudiée. Or ce puceron est fréquemment observé dans les cultures françaises de prunier, pêcher, abricotier (Leclant, 1973). II hiverne, sous forme de femelles vivipares parthénogénétiques, au collet de l'arbre, sur les grosses racines ou sous les branches basses. Les individus remontent au printemps dans la couronne de l'arbre. Ils colonisent les jeunes pousses dont ils provoquent la déformation en crosse. Ils sont particulièrement nuisibles en pépinières (Anonyme, 1974a).

La réussite de la transmission expérimentale du virus de la sharka par puceron dépend de plusieurs facteurs, notamment l'espèce et la forme, aptère ou ailée, du vecteur (Massonié et Maison, 1986), l'isolat géographique du virus (Marenaud et Massonié, 1977), l'espèce végétale et les cultivars (Massonié et Maison, 1986 ; Dosba et al, 1987, 1992), les techniques de transmission du virus (Maison, 1984). Ces dernières, en relation avec le choix de l'organe inoculé et le nombre de piqûres d'inoculation, ont aussi un rôle important. 
Tableau I. Pucerons vecteurs de la sharka.

\begin{tabular}{|c|c|}
\hline Myzus persicae (Sulzer) & Kunze et Krczal (1971) \\
\hline Phorodon humuli (Schrank) & Kunze et Krczal (1971) \\
\hline $\begin{array}{l}\text { Brachycaudus helichrysi } \\
\text { (Kaltenbach) }\end{array}$ & Kunze et Krczal (1971) \\
\hline $\begin{array}{l}\text { Brachycaudus cardui } \\
\text { (Linné) }\end{array}$ & Kunze et Krczal (1971) \\
\hline Myzus varians Davidson & Leclant (1973) \\
\hline Aphis spiraecola Patch & Leclant (1973) \\
\hline Aphis craccivora Koch & Leclant (1973) \\
\hline $\begin{array}{l}\text { Hyalopterus pruni } \\
\text { (Geoffroy) }\end{array}$ & $\begin{array}{l}\text { Minoiu (1973) } \\
\text { Kunze et Krczal (1970): } \\
\text { non vecteur }\end{array}$ \\
\hline Aphis fabae Scopoli & Llacer et al (1991) \\
\hline $\begin{array}{l}\text { Brachycaudus persicae } \\
\text { (Passerini) }\end{array}$ & $\begin{array}{l}\text { Fos et Massonié (1993) } \\
\text { (présente publication) }\end{array}$ \\
\hline
\end{tabular}

Les jeunes plants issus de semis des 2 variétés précitées sont inoculés lorsque leur tige atteint, suivant les essais, une hauteur comprise entre 15 et 25 $\mathrm{cm}$. Ils présentent lors de leur inoculation une croissance vigoureuse. Les conditions de leur culture en serre climatisée sont identiques, exception faite de l'éclairement naturel, qui varie d'un essai à l'autre.

Le virus est représenté par l'isolat grec Marcus, choisi car très pathogène sur pêcher (Marenaud et Massonié, 1977). Cet isolat est maintenu au laboratoire depuis 1989 sur de jeunes plants de GF305 inoculés par $M$ persicae.

Les tentatives de transmission sont effectuées en déposant sur chaque plant 20 pucerons, qui ont auparavant subi un jeûne de 2 à $4 \mathrm{~h}$.

Deux techniques sont utilisées. Elles diffèrent essentiellement par le temps de présence des insectes.

\section{Méthode A}

L'apex de la plante à inoculer est enfermé dans une cagette en plastique transparent et grillagé. Une feuille excisée de GF305 présentant les symptômes de la maladie et hébergeant les pucerons y est introduite. Après un délai de $24 \mathrm{~h}$, la cagette est enlevée et les pucerons sont éliminés par un lavage à l'eau et un traitement aphicide.

\section{Méthode B} persicae. Deux techniques de transmission ont été utilisées: l'une très favorable à la réussite des transmissions, afin de mettre en évidence le caractère éventuellement vecteur du puceron, l'autre peu favorable, afin de tenter une estimation de l'efficacité du vecteur. Afin de disposer de bases de comparaison, les essais comprennent également les transmissions par Myzus persicae Sulzer, vecteur de référence.

\section{MATÉRIEL ET MÉTHODES}

Les tentatives de transmission sont réalisées soit avec des aptères, soit avec des ailés. Les jeunes adultes de $M$ persicae sont prélevés dans un élevage de masse constitué en 1988 à partir d'une fondatrice sur pêcher, puis maintenu sur des semis du pêcher GF305 cultivés en pièce climatisée. Les adultes de $B$ persicae proviennent des colonies naturelles installées sur des plants de pépinière des cultivars de pêcher GF305 et Rubira.

Les cultivars de pêcher Prunus persica (L) Batsch GF305 et Rubira (clone S 2605) sont des portegreffes. GF305 est colonisé par les 2 espèces de pucerons, Rubira n'est colonisé que par $B$ persicae (Massonié et Maison, 1979 ; Massonié et al, 1982).
Les pucerons sont déposés pendant 2 min sur une feuille excisée de GF305 présentant les symptômes de la maladie puis transférés sur l'apex encagé du plant à inoculer. Ils y sont laissés $5 \mathrm{~min}$, puis éliminés comme indiqué précédemment.

Les plants inoculés sont transférés dans une pièce climatisée: $16 \mathrm{~h}$ de jour, $30 \mu \mathrm{mol}$ photons $\mathrm{m}^{-2} \bullet \mathrm{s}^{-2}$, température comprise entre 20 et $25^{\circ} \mathrm{C}, 70$ à $90 \%$ d'humidité relative.

Après une période d'incubation de 10 à $20 \mathrm{j}$, les symptômes de la maladie apparaissent. La réussite des transmissions est alors associée à l'apparition des symptômes. Le diagnostic visuel est confirmé par la technique sérologie Elisa (Dunez, 1977).

\section{RÉSULTATS}

Dans nos conditions expérimentales (tableau II) : - $B$ persicae transmet le virus de la sharka à des semis de pêcher; les taux de transmission sont relativement élevés (35 à $67 \%$ selon le cas) ;

- la forme ailée de $B$ persicae paraît transmettre plus efficacement que la forme aptère $(67 \%$ 
Tableau II. Nombre de plants de pêcher présentant les symptômes de la sharka après une tentative de transmission expérimentale du virus par des pucerons.

\begin{tabular}{lccc}
\hline Pucerons & $\begin{array}{c}\text { Cultivars } \\
\text { de pêcher }\end{array}$ & $\begin{array}{c}\text { Résultat des transmissions } \\
\text { No de plants positifs/ } \\
\text { No de plants testés }\end{array}$ \\
\cline { 3 - 4 } & & Technique A & Technique B \\
\hline Myzus persicae & GF305 & $41 / 50$ & $11 / 25$ \\
Aptères & Rubira & $4 / 26$ & $4 / 10$ \\
$\begin{array}{l}\text { Brachycaudus } \\
\text { persicae } \\
\text { Aptères }\end{array}$ & GF305 & $7 / 20$ & $2 / 5$ \\
Brachycaudus & Rubira & $9 / 20$ & $1 / 15$ \\
persicae & & & - \\
Ailés & GF305 & $14 / 21$ & - \\
\hline & Rubira & $5 / 10$ & - \\
\hline
\end{tabular}

contre $37 \%$ ) le virus de la sharka à la variété sensible GF305 $\left(\chi^{2}=4,11\right)$; en revanche les résultats des transmissions effectuées sur Rubira ne semblent pas être affectées par la forme $\left(\chi^{2}=\right.$ $0,067)$;

- les aptères de $B$ persicae transmettent moins efficacement que ceux de $M$ persicae le virus de la sharka à GF $305\left(\chi^{2}=12,2\right)$ mais sont plus performants sur Rubira $\left(\chi^{2}=6,25\right)$.

\section{CONCLUSION}

Nous signalons pour la première fois, par 2 méthodes expérimentales et sur 2 variétés de pêcher, que les formes aptères et ailées de $B$ persicae peuvent transmettre le virus de la sharka. La transmission du virus par cette espèce pourrait donc intervenir en verger. L'espèce $B$ persicae représente donc un danger potentiel qui justifie de mesures de lutte en culture de Rosacées fruitières sensibles à la maladie.

\section{REMERCIEMENTS}

Nous exprimons nos remerciements à Mme Dosba, directeur du Laboratoire de recherches fruitières et à ses collaborateurs qui ont effectué la détection du virus de la sharka par la méthode Elisa.

\section{RÉFÉRENCES}

Anonyme (1974a) Puceron noir du pêcher. In : Contrôles périodiques en verger. ACTA Lutte Intégrée, Paris, $49 p$

Anonyme (1974b) Progrès réalisés dans la connaissance de la sharka. Bull OEPP 4, 1-125

Avinent L, Hermoso de Mendoza A, Llacer G (1991) Comparison of traps for capture of alate aphids (Homoptera, Aphidinae). agronomie 11, 613-618

Dosba F, Maison P, Lansac M, Massonie G (1987) Experimental transmission of plum pox virus (PPV) to Prunus Mahaleb and Prunus avium. J Phytopathol 120, 199-204

Dosba F, Orliac S, Dutrannoy F, Maison P, Massonie $\mathrm{G}$, Audergon J (1992) Evaluation of resistance of plum pox virus. Acta Hortic 309, 211-220

Dunez J (1977) Application des techniques immunoenzymatiques à la détection de certains virus pathogènes des végétaux. La méthode Elisa (enzyme linked immunosorbent assay). Ann Phytopathol 9, 219-221

Jordovic $M$ (1965) The rate of spread of sharka (plum pox) virus on some plum varieties in nature. Zast Bilja 18, 353-356

Kassanis B, Sutic D (1965) Some results of recent investigations on sharka (plum pox) virus disease. Zast Bilja 18, 335-340

Kunze L, Krczal H (1970) Transmission of sharka virus by aphids. Ann Phytopathol HS, 255-262

Labonne G, Quiot JB, Hubert I (1988) Les pucerons vecteurs de la sharka dans un verger d'abricotier du sud-est de la France. Premiers résultats. In : Agriculture. L'abricotier (Audergon JM, ed) Comm Commun Eur, Luxembourg 25-32

Lansac M, Bernhard R, Massonie G, Maison P, Kerlan C, Dunez J, Morvan G (1982) La sharka : connaissances actuelles. In: Les maladies des plantes. ACTA, Paris, 452-468

Leclant F (1973) Aspect écologique de la transmission de la sharka (plum pox) dans le sud-est de la France. Ann Phytopathol 5, 431-439

Llacer G, Avinent L, Hermoso de Mendoza A (1992) Epidemiology of plum pox (sharka) virus in Valencia (Spain). Acta Hortic 309, 129-134

Maison P (1984) La transmission par pucerons du virus de la sharka à des variétés de pêchers. Thèse de l'université de Bordeaux I

Marenaud C, Massonié G (1977) Étude comparative de différents isolats du virus de la sharka. Ann Phytopathol 9, 107-121

Massonié G (1976) Pucerons et transmission de la sharka 13-20. In : La sharka. INVUFLEC, Paris, 1320

Massonié G, Maison P (1979) Résistance de 2 variétés de Prunus persica (L) Batsch à Myzus persicae 
Sulzer et à Myzus varians Davids: étude préliminaire des mécanismes de résistance. Ann Zool Ecol Anim 11, 4474-4485

Massonié G, Maison P (1986) Investigations on the resistance of peach varieties to aphid transmission of plum pox virus. Acta Hortic 193, 207-212
Massonié G, Maison P, Monet R, Grasselly C (1982) Résistance au puceron vert du pêcher Myzus persicae Sulzer chez Prunus persica $(L)$ Batsch et d'autres espèces de Prunus. agronomie 2, 63-70

Minoiu N (1973) Vectorii virusului varsatului la prun. Ann ICPP 9, 49-56 